
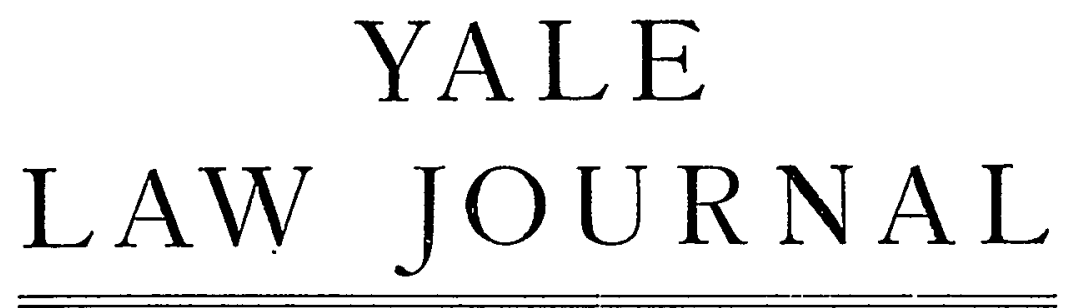

\begin{tabular}{lll}
\hline VOL. VII NOVEMBER, 1897 & No. 2 \\
\hline
\end{tabular}

\title{
SOME PECULIARITIES OF OUR NATIONAL MINING LAW.
}

To the minds of those familiar with the common law governing the acquisition of title and the ownership of real property, many of the rules applicable to mining rights under the Acts of Congress will appear, to say the least, anomalous. Such radical departures from the common law have been made that, at first blush, one would be impelled to say,-This cannot be. It must be remembered, however, that the Acts of Congress apply only to mining rights upon the public domain. The general government, being the absolute proprietor of the lands in which these mines are found, has full power and authority to determine how such rights may be initiated and continued, how they may ripen into absolute title, and what extraordinary rights may be acquired and vested with them.

Time and space will permit only a most cursory reference to some of the peculiar rules governing the acquisition, use and ownership of this class of property, and peculiar rights attaching thereto.

Ordinarily, no fixed rights to the agricultural lands of the government can be acquired, until after they have been surveyed under governmental supervision, but mines may be located and patented on unsurveyed as well as upon surveyed lands. All of the unoccupied public domain containing any of the minerals mentioned in the statute is open to exploration, appropriation and purchase. It is proper to say, however, that this law does not apply to the older States in which there is no public domain, nor does it apply to the States of Michigan, Wisconsin and some others, by express exception in the Act itself. 
Any person, a citizen of the United States, or who has declared his intention to become such, is qualified to enter upon the unappropriated public mineral lands of the United States, and initiate a right or title to a mining claim.

Reference will be made to only three of the many peculiarities of this law:

First: The origin of the law.

Second: The method of initiating the right, and of its continuance.

Third: The extralateral rights.

The consideration of these subjects should probably be prefaced by the explanation that these laws recognize and pro. vide for two general classes of mines or mining rights, viz., claims upon veins, leads, lodes or ledges; and claims upon placers. The classification depends upon the character of the deposit, and while the general rules for the acquirement and continuance of rights to each class of claims are the same, there are many differences in the law applicable to collateral rights thereunder.

Theoretically, at least, all precious metals are supposed to have been originally deposited under the same general conditions, viz., in fissures, rents, cracks or crevices in the earth's crust formed by some force of nature, or along the contact between different rock formations. The precious metals thus deposited are found intermingled with quartz or other rock in the crevice or fissure, or along the contact; or in combination with other metals found therein. This fissure, crevice or cortact, with its filling, is known as the vein, lead, lode or ledge.

Placer claims or mines are those where, by processes of nature, the gold has been removed from these fissures or crevices, separated from its former companions, and deposited in a comparatively pure state among the earth, gravel and debris, along the streams and creeks, and the benches adjoining.

It would be useless to attempt to explain the operation of the forces of nature which have brought about these existing conditions. The law recognizes things only as it finds them, and does not concern itself with the method by which they are brought about.

FIRST: THE ORIGIN OF THE LAW.

Prior to the discovery of gold in California it is believed that nothing approaching the present mining law existed in this country. It first rested in the customs of miners, and their mining rules and regulations, adopted in the different districts. It 
was then recognized by the Legislature and courts of California upon their organization, and subsequently crystallized into statute law by an Act of Congress of the United States.

Its origin and development furnish an interesting page in the history of our country. Considering the conditions existing immediately after the discovery of gold in California we can but be amazed at the order which was wrought by the miners, out of existing chaos. Thousands of all classes of people flocked there, allured by visions of sudden wealth. The worst elements of society were well represented, because of the opportunities afforded to ply their nefarious vocations. The country was new, the interests novel, and there were no positive rules of law to guide the miners, and if there had been, there were at first no organized courts to which they could apply to settle their difficulties, protect their rights and redress their wrongs. In the absence of all these, the miners were compelled to take care of themselves and their property, and at an early day, by common consent, recognized certain usages and customs, and adopted certain rules and regulations for their guidance. They made their own laws, established their own courts, and enforced obedience thereto. In many instances their proceedings were summary, but necessarily so in order to be effective. Probably many of them had worked in the tin mines of Devon or Cornwall, or in the lead mines of the County of Derby, and were familiar with the laws applicable to this peculiar species of property in force there; many probably came from the southern country, and brought with them the customs, usages and rules of the Spanish and Mexican mining laws. Many of these customs were of extremely ancient date. Doubtless great assistance in formulating these mining rules and customs was derived from these sources. The American himself probably was absolutely wanting in experience of this kind. However this may be, sure it is that a majority of them were impressed with wholesome ideas of justice and equity, between man and man.

Chief Justice Sanderson of California uses the following very apt language, with reference to these customs and usages: "These usages and customs were the fruits of the times, and demanded by the necessities of communities, who, though living under the common law, could find therein no clear and well defined rules for their guidance applicable to the new conditions by which they were surrounded, but were forced to depend upon remote analogies of doubtful application and unsatisfactory results." 
Illustrating the love of justice and equity which predominates in our people everywhere, these miners, as if by common consent, adopted the rule that discovery of the precious metals was the basis of a mining right, and that to him who made the discovery should go the fruits thereof. The custom was recognized among them that he who discovered the metals had the first right to appropriate to his use a reasonable amount of the surface of the ground in which they were found. It can be readily seen that without the adoption of some rule of this character, none would have been safe in any rights. Scrambling possession would have followed, broils would have been engendered, and physical force would have been the test of right. But this was all settled amicably and equitably, by all the miners protecting each other in the discovery of mineral in his claim, and in the exclusive possession of the ground containing such mineral.

The second step recognized by the miners was the appropriation or location of mining rights or claims, by the person making the discovery. After this was recognized it appeared that some rule was riecessary to provide how the rights thus initiated should be continued. The object of all the miners was, to extract the precious metals from the earth, and it seemed proper that no one should be allowed to practice the act of the dog in the manger. No one ought to appropriate the land and the minerals therein, and allow them to rest undeveloped. For the purpose of settling this question it was determined that the holder of each claim should work and develop it, as a condition of continued possession. Of course all were trespassers. The general government was the absolute owner of the ground, and of all the minerals contained therein, but so long as the Government made no objection-did not try to eject the miners from their claims or compel them to account for the precious metals they found-they continued their operations under their own laws.

These laws were strictly enforced by the miners, although they rested purely in custom, ùsage and adopted rules. They had only the inherent force of law, because of the determination of the miners that, for their own protection, they should be obeyed.

It is a great compliment to the sagacity, common sense and inherent ideas of right and justice of the early miners in California, that the three principal rules relative to the acquirement of mining claims as thus established by them were recognized by 
the courts and Legislature of California, as soon as they were organized, and that they were subsequently made the basis of the present mining law by Acts of Congress.

The organization of mining districts and the adoption of rules and regulations, customs and usages by the miners in such district, governing all alike within their respective boundaries, are equally interesting, but want of space forbids any further reference.

In 1866 Congress enacted a law, recognizing the possessory rights of miners, and later, during the same session, enacted a law whereby the veins, leads, lodes or ledges could be patented to the claimants; only possessory rights to placer claims were recognized until 1870 , when Congress provided a method for the claimant to procure absolute title also to that class of property by patent.

In 1872 Congress modified the Act of 1866 and reënacted the placer Act of 1870 , and in effect codified the general mining laws of the United States, and, with few amendments since adopted, this Act is now the law in force.

\section{Second: The Method of Initiating the Right, AND of its Continuance.}

Although the provisions of the law relative to the location of claims on veins or lodes, are made applicable to the location of placers, as far as possible, there are some departures and some rules relative to claims on veins, lodes, leads or ledges, which do not apply to placers, and for the purpose of reaching the broader class, reference will only be made to the latter.

Inasmuch as only public lands valuable for the minerals mentioned in the statute are open to appropriation, the first question to be determined is the character of the land, i. e., whether or not it is mineral. In view of this the statute, following the customs of miners as hereinbefore referred to, has provided that the initial step in the acquirement of a mining claim shall be that of discovery. This is the acquirement of knowledge of the existence, in the ground sought to be appropriated, of some one or more of the minerals mentioned in the statute. When discovery of any of these minerals is made in a vein and of sufficient value to warrant exploitation with a reasonable belief that it will be found in paying quantities, it is sufficiently demonstrated that the character of the land sought to be appropriated is mineral, and is therefore rendered susceptible of appropriation under the statute. 
The mineral character of the land having been determined by a discovery, the next step toward a complete appropriation is designating the surface area sought to be claimed. This is accomplished by marking the claim sought to be appropriated, so that its boundaries can be readily traced upon the ground. The marking consists of placing properly marked stakes or monuments, or marking blazed trees, at each corner of the claim, and at such other points along the boundary lines as may be required by local rules or regulations and the statutes of the State or Territory in which the location is sought to be made. The claimant on a lead, lode, vein or ledge is allowed a surface area of 600 by $I, 500$ feet- 1,500 feet along the course or strike of the vein, and 300 feet wide on each side from the center of the vein. An ideal location, therefore, is a parallelogram 600 by I, 500 feet, with the vein running through the center from end to end. The lines which mark the width of the claim and cut the course of the lead or vein are denominated "end lines"; those which mark the length of the claim, and, theoretically, run parallel to the course or strike of the vein, are denominated "side lines."

The next step in the appropriation of the claim is the posting of a notice upon the claim (unless some local rule, regulation or custom, or the statute of the State or Territory requires it, this need not be done). This notice, when required, usually contains a statement that the locator or claimant is a citizen of the United States, or has declared his intention to become such: that he has complied with the provisions of the Act of Congress, and the local rules, regulations and customs of miners, and the statutes of the State or Territory; that he claims a certain distance along the vein or lode, each way from the point of his discovery, not exceeding ' $\mathrm{x}, 500$ feet in all, with a width of not exceeding 300 feet on each side of the center of the lode or vein; it then gives a general reference to the locality in which the claim is located; then follows a specific description of the markings of the boundaries of the claim; it concludes with the date of the location and the name of the claimant. This notice should be posted at or near the point of discovery, so that any other prospector will be able to see it, and ascertain therefrom that a certain portion of the public domain has already been appropriated, and govern himself accordingly.

Congress authorizes the miners of the district, or the Legislature of the State or Territory, to require a record of the location to be then made, and provides that if such record be required it 
shall contain the name of the locator, the date of the location, and such a reference to some natural object or permanent monument as will identify the claim. Such record is usually required and when required it is one of the steps necessary to be taken in completing the location. The record is made by recording in the office of the Register of Conveyances in the county where the claim is situated, or if there be no county organization, with the District Recorder, a notice or declaratory statement of the location, containing the matters required by Congress and the local rules or statutes, to be stated therein. The effect of a valid location is to segregate the area located from the public domain, and the claimant acquires a species of title therein which is denominated real-estate. Indeed, it has all the attributes of real-estate. It may be conveyed, seized and sold under process, and descends to the heirs. So long as the claimant complies with the conditions of continued possession prescribed by the law, even the government itself cannot oust him or forfeit his right. True, the legal title is in the government until patent is issued, but it is held in trust for the locator, and relates back, upon the giving of patent, to the date of location.

The condition of continued possession and ownership is, that the claimant, until final entry in the Land Office upon application to purchase, shall perform at least one hundred dollars' worth of work on the claim each year. This may be done at any time from January ist to December 3 rst of each year. If it is not done, or not fully done, the location and all the rights of the claimant therein are forfeited. The land reverts to the public domain, and again becomes open to location by any qualified person. The law, however, gives the claimant one further opportunity, by providing that no forfeiture shall take place if the claimant, before other rights intervene, recommences on the claim in good faith. But he must then complete at least one hundred dollars' worth of work upon the claim.

The process by which patent is obtained, in the absence of adverse claims, is very simple, and it would serve no useful pur. pose to go into detail in regard to it.

THIRD: THE EXTRALATERAL RIGHT.

One peculiarity of a vein, lode, lead or ledge, is that it almost always, on its descent into the earth, departs from the perpendicular, the angle of departure so varying as to leave the vein in any position from one almost perpendicular to one almost horizontal. This departure is called, in mining parlance, 
the "dip" of the vein or lode. The run or length of the lode horizontally is called its "strike" or "course." The top of the vein or lode, or that portion next the surface of the earth, is denominated its "apex."

Of course the value of the mine is in the veins or locles, and the surface ground is in the nature of an inciclent, to enable the claimant to properly carry on his mining operations in connection with his veins or lodes. In many instances the dip of the vein is so great that, in its descent into the earth it soon passes through a plane dropped perpendicularly through the exterior boundary line of the claim, toward which it dips. Under the ordinarily recognized rule of real-property the owner of the vein, as soon as it passed through this plane, would lose all right to it, and it would belong to the adjacent proprietor into whose ground it passed. Many veins show but little value before this point of departure is reached, and if the owner of the claim then lost it, and the adjacent proprietor acquired it, the claimant might have spent many thousands of dollars in developing a mine for his neighbor, who, possibly, had made no expenditure.

Congress recognized the inequity of such result, and for the purpose of avoiding it, and as a premium to the man who is willing to spend his money in developing his property and adding something to the substantial wealth of the nation, enacted the following as a part of the general mining law: "The locators of all mining locations heretofore made or hereafter to be made on any mineral vein, lode or ledge situated on the public domain, their heirs and assigns *** shall have the exclusive right of possession and enjoyment of all the surface included within the lines of their locations, and of all the veins, lodes and ledges throughout their entire depth, the top or apex of which lies inside of such surface lines extended downward verticalls, although such veins, lodes ur ledges may so far depart from a perpendicular in their course downward as to extend outside the vertical lines of such location. But their right of possession to such ontside parts of such veins or ledges shall be confined to such portions thereof as lie between vertical planes drawn downward as above described, through the end lines of their locations, so continued in their own directions that such planes will interest such exterior parts of such veins or ledges. And nothing in this section shall authorize the locator or possessor of a vein or lode which extends in its downward course beyond the vertical lines of his claim, to enter upon the surface of a claim owned or possessed by another."' 1

1 Sec. 2322, Revised Statutes U. S. 
One would think that the extralateral right hereby granted was most easy of enforcement; that the statute was plain and required no construction. If all locations were such as the statute contemplated, this conclusion would be correct. Recalling your attention for a moment to an ideal location. You can readily see therefrom what was intended by this section, and appreciate how easily it could be applied. Imagine a rectangular piece of surface ground 600 by 1,500 feet, with a vern, on its course or strike, running lengthwise through the claim from end line to end line, with its center equidistant from the two side lines, as shown in Fig. $x$.

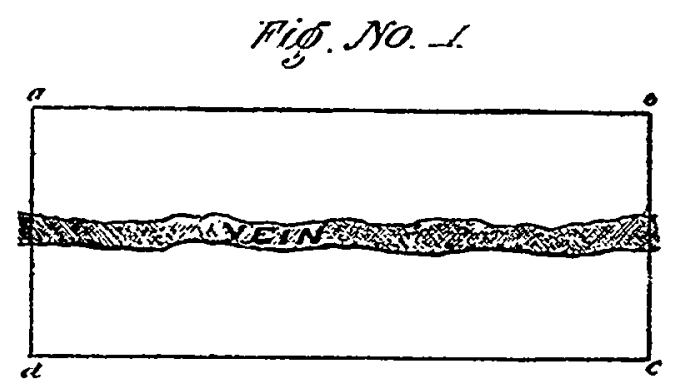

Suppose the vein dips to the south; taking a cross-section of the ground we see the vein on its dip, passing through the south side line of the location. Fig. 2.

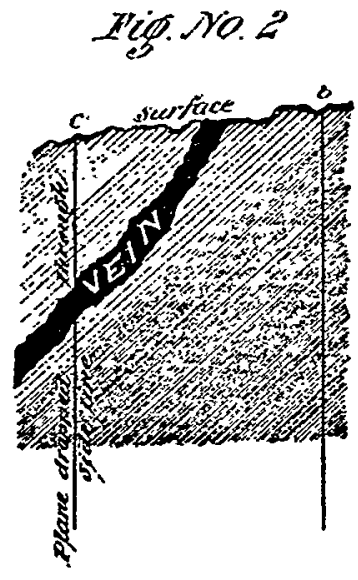

Under such circumstances the intent of the statute is quite plain and no disputes could arise. The locator having $x, 500$ feet of the vein on its strike or course would have an equal amount on the dif to an indefinite depth.

Unfortunately, and ideal location is the exception instead of the rule. Indeed, when we consider the existing conditions at the time of location, we must wonder that an ideal location is ever met with. As a rule, wherever veins are found the surface of the ground is rugged and irregular, frequently covered by a dense growth of timber. The apex of the vein at one end of the location may be near the surface, or even exposed, while at the other end it may be buried many feet deep. Again, veins seldom run, on their course or strike, in a straight line. Many conditions may influence this-the contour of the country, such as the hills or the ravines. Natural influences at or after the formative period may have disturbed it. In 1,500 feet, or the length of the location, the course of the vein may change many degrees. So that, without actual exposure of the apex of the 
vein for the entire length of the claim, before marking the boundaries of a location, the prospector has no means of being assured that his vein passes through the claim as located, from end line to end line. To expose the vein for the entire $r, 500$ feet before marking the boundaries of the location would require more time than the statutes usually allow, and, in many instances, more money than the average prospector could possibly expect to obtain during his natural lifetime. The prospector therefore must use his best judgment in laying his location, and must bear the consequences if he makes a mistake.

To illustrate the results, even where sufficient unoccupied

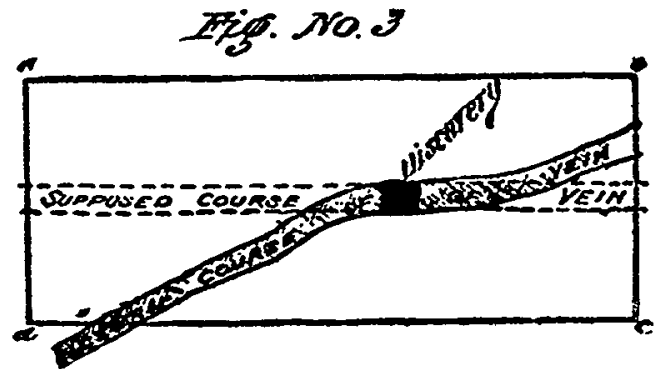
ground is found to make a full location, consider Fig 3.

Let the small square on the vein represent the place of discovery. The prospector traces the vein, we will say, to the east, sufficiently far to obtain an idea of its general direction. He then projects this course to the east and west of his discovery, to the extent of $\mathrm{I}, 500$ feet. He then marks his location upon that theory. If the vein continues in the supposed direction through the claim it might be represented by the two dotted lines. Upon subsequent development, however, the prospector finds that the course of the vein in his location is actually as represented by the black line, the vein passing out of the claim at the east end line and at the south side line.

The effect of such complications, and others, will be called to your attention later on.

Two principles have been announced by the Supreme Court of the United States relative to Section 2322 :

First. That wherever a vein cuts the boundary line of a claim on its course or strike, such line becomes an end line, in so far as the application of the law of extralateral rights is concerned, and this irrespective of the designation the locator may have given to the particular line, upon the ground.

Second. That in order that a claim should have extralateral rights, its end lines, as determined by the course or strike of the vein in cutting the boundaries of the claim, must be parallel.

Applying these two principles to actual conditions as devel- 
oped, many problems difficult of solution present themselves, although the section above quoted seems clear. I am of the opinion that under certain circumstances the Supreme Court will follow the later decisions of the Federal Courts and some of the State courts of last resort, and modify the second proposition for the purpose of preventing the destruction of extralateral rights in certain cases. It would extend this article to an unwarranted length to attempt to discuss or determine the extent of extralateral rights in particular cases. We will content ourselves for: the present by calling attention to the many difficulties to be

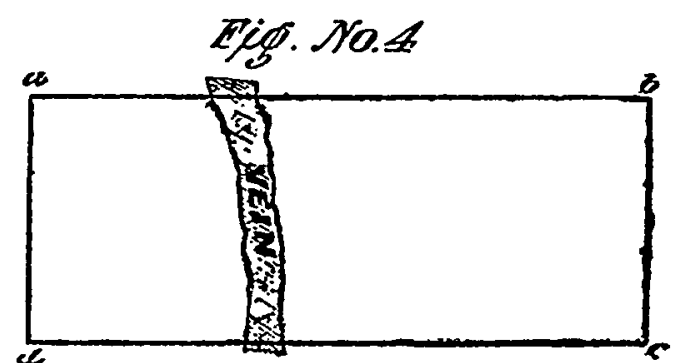
encountered in applying the above section of the statute, and for that purpose some illustrations may be presented.

Suppose the vein passes through the location as shown in

side lines. Where are the extralateral rights here? Fig. 4, cutting both

Suppose another situation where the vein passes in and out of the same side line. See Fig. 5. What is to be done under these conditions?

Again, suppose all the ground except a triangle has been patented and a prospector discovers a valuable vein within the surface ground of this triangle and locates a claim. Of

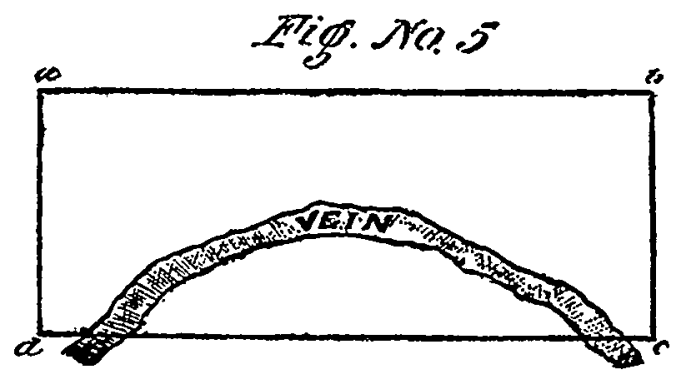
course he can only acquire the surface rights to the vacant land. The land between the patented claims A, B, C, in the form of a triangle, is open to location, and a vein runs through it. See Fig. 6. Suppose a prospector locates it and the vein dips towards the claim marked $B$; what are his extralateral rights? He can have no parallel lines at all for the vein to pass through on its course.

As a further illustration, suppose the vein on its course passes through an end line, and a side line of the location as marked by the locator on the ground, as shown in Fig. 7. If 
both lines cut by the vein on its strike are end lines, in so far as extralateral rights are concerned, and such end lines must be

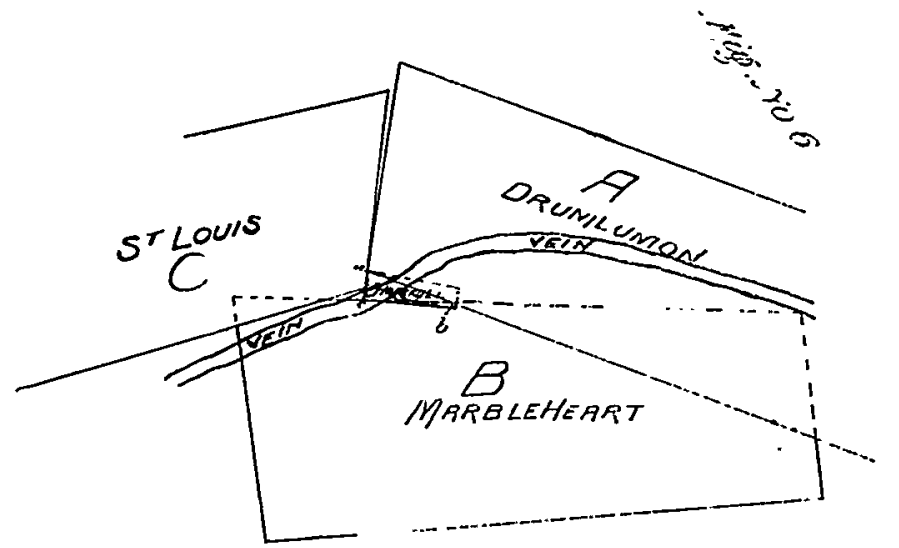

parallel to give extralateral rights, the problem presented is not easy of solution, unless we say no extralateral rights attach to such conditions. Our courts, however, have made an equitable determination of this, which it is believed the Supreme Court of the United States will eventually adopt.

One more condition may be referred to. See Fig. 8. In this instance a location was sought to be

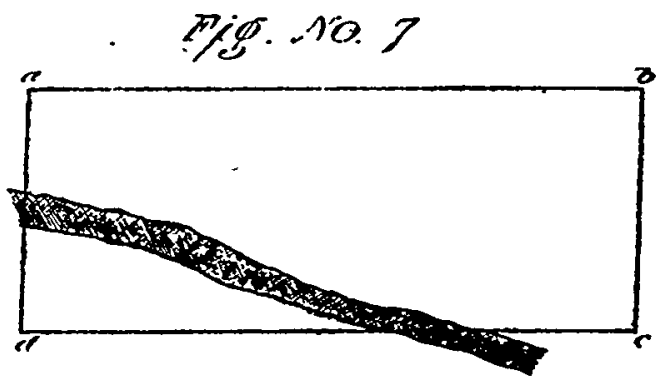
made of a vein presenting a semi-circular apex. There is no objection to making a location in this or in any other shape. There is no requirement that a location shall be in the form of a parallelogram, or that it shall have any particular number of boundary lines, or that any of its lines, except the end lines, shall be parallel.

All of these illustrations are practical questions, which mining lawyers and the judges are called upon to solve, and all of them are actual cases, already considered and decided by the courts.

To make the application of the doctrine of extralateral rights a little more complicated and uncertain, questions frequently 
arise as to whether the vein found in the adjacent ground, is really the same vein which has its apex in the claim of the locator. Veins are as erratic on the dip as on the strike. Forces of nature have played with them in the same way, and may have thrown parts of the vein, with its enclosing formation, many feet out of the place ir which it originally existed. So that, in some instances, it is almost, if not entirely, impossible to show continuity of the vein, from the claim having the apex thereof, into the adjacent ground. For example, take a crosssection of a location with the underground vein as shown in Fig. 9 .

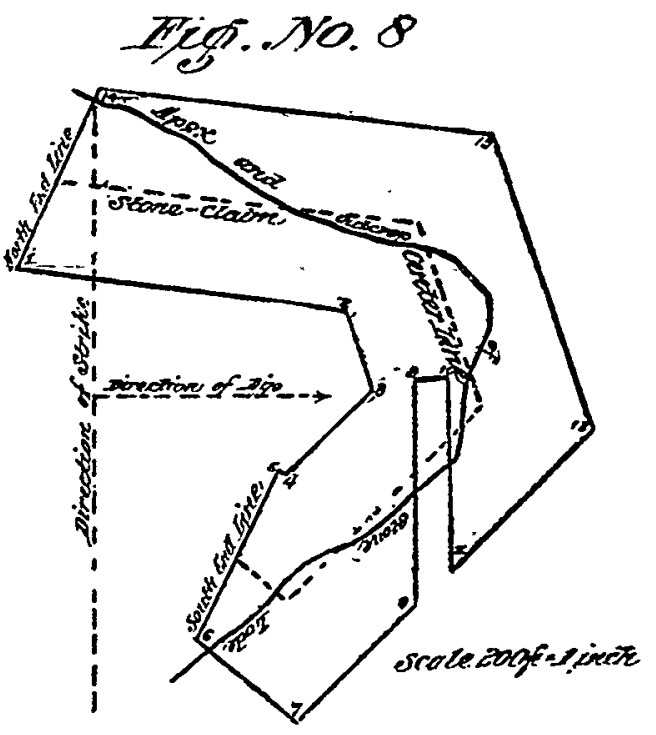
The veins $A$ and $B$ may at one time have been parts of the same vein, $B$ having been a continuation of $A$. Through some operation of the forces of nature the entire formation within the location including the vein is dropped down, completely breaking off the vein and removing it many feet from its former position. If the owner of the location claims the right to follow the vein upon its dip into the adjacent ground he must be prepared to prove that vein $B$ is a continuation and portion of vein $A$. One

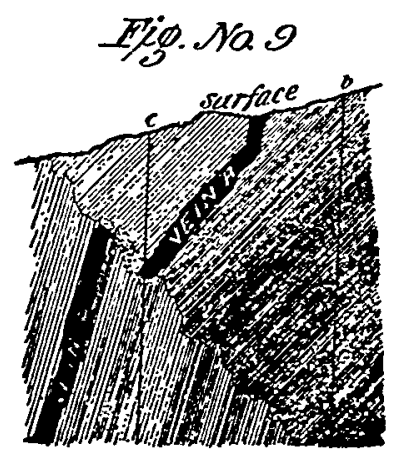
can readily imagine how difficult this may be, especially when the development of the vein from the surface down to the point of breakage, and from the top of vein $B$ towards the surface has not been completed.

Again, frequently the walls or sides of the vein upon its dip approach so closely together as to leave it questionable whether the vein itself does not entirely cease. Further development, however, downward, on the line of the vein extended may show another ore body or vein. 
The question then for determination is, whether these two parts are all one vein, or whether they are two separate veins.

It is apparent, therefore, that many difficult and interesting questions have arisen under the apparently plain terms of this section, and it is more than probable that other complicated conditions will develop presenting other equally difficult problems.

In conclusion, I cannot refrain from saying that the general subject of mining law is constantly growing in importance, and yet there is less known about it, and less effort made to furnish law students an opportunity to familiarize themselves with it, than any other branch of jurisprudence. The student who expects to practice his profession in the large cities of the East should not delude himself into the belief that it will be unimportant to him. It must be remembered that millions of dollars of capital from eastern moneyed centers are invested in mining enterprises, and a well-equipped lawyer should be prepared to advise his client with reference to all his business and legal transactions.

Helena, Mont., November I.

Jno. B. Clayberg. 